\title{
Association of Adiponectin Gene Polymorphisms With the Risk of Coronary Artery Disease in Patients With Nonalcoholic Fatty Liver Disease in a Chinese Han Population
}

\author{
Shui-Xian Du, ${ }^{1,2}$ Lin-Lin Lu, ${ }^{3,4}$ Yang Liu, ${ }^{1,2}$ Quan-Jiang Dong, ${ }^{2,3}$ Shi-Ying Xuan, ${ }^{1,2,3,{ }^{*}}$ and Yong-Ning Xin ${ }^{1,2,3,{ }^{*}}$ \\ ${ }^{1}$ Medical College of Qingdao University, Qingdao, China \\ ${ }^{2}$ Department of Gastroenterology, Qingdao Municipal Hospital, Qingdao, China \\ ${ }^{3}$ Digestive Disease Key Laboratory of Qingdao, Qingdao, China \\ ${ }^{4}$ Central Laboratories, Qingdao Municipal Hospital, Qingdao, China \\ "Corresponding authors: Yong-Ning Xin, Medical College of Qingdao University, Qingdao, China. Tel: 86-53282789463, Fax: 86-53285968434, E-mail: xinyongning@163.com; \\ Shi-Ying Xuan, Medical College of Qingdao University, Qingdao, China. Tel: +86-53288905508, Fax: +86-53288905293, E-mail: xuansydxy@163.com
}

Received 2016 February 24; Revised 2016 May 11; Accepted 2016 May 31.

\begin{abstract}
Background: Cardiovascular events are an independent risk factor for nonalcoholic fatty liver disease (NAFLD), which is the leading cause of mortality in NAFLD patients. Several recent studies demonstrated that adiponectin (Ad) polymorphisms were involved in the progression of NAFLD and coronary artery disease (CAD). However, reports on the association between Ad polymorphisms and the risk of developing CAD in NAFLD patients are lacking in a Northern Han Chinese population.

Objectives: The present study was designed to evaluate the association between Ad gene polymorphisms ( $r s 266729$ and $r s 2241766$ ) and the risk of developing CAD in Northern Han Chinese patients with NAFLD.

Materials and Methods: In this case-control study, using the polymerase chain reaction (PCR), Adrs266729 and rs2241766 gene polymorphisms were genotyped in B-type ultrasonography-proven NAFLD patients, with $(n=246)$ or without $(n=247)$ CAD and in healthy controls $(n=304)$. Serum lipid profiles were determined using biochemical methods. Statistical analyses were performed using SPSS 17.0 statistical software.

Results: There were significant differences in the Adrs266729 G allele between the NAFLD patients with and without CAD (P< 0.05). In addition, there was a significant difference in the Adrs2241766 G allele of the NAFLD patients compared with that of the controls $(\mathrm{P}<0.05)$. In the NAFLD CAD population, carriers of the $\mathrm{G}$ allele of Adrs266729 had higher serum triglycerides (TG), total cholesterol (TC), fasting plasma glucose (FPG), and low-density lipoprotein (LDL) levels and a lower Ad level than their noncarrier counterparts $(\mathrm{P}=0.031, \mathrm{P}=0.034, \mathrm{P}=0.007, \mathrm{P}<0.001$, and $\mathrm{P}<0.001$, respectively). NAFLD patients without $\mathrm{CAD}$ had higher TG and serum FPG values and a lower Ad level than their noncarrier counterparts $(\mathrm{P}=0.014, \mathrm{P}=0.038$, and $\mathrm{P}<0.001$, respectively). In the NAFLD patients with/without CAD, the carriers of the $\mathrm{G}$ allele of Adrs2241766 had higher TG levels ( $\mathrm{P}=0.039$ and $\mathrm{P}=0.042$, respectively) than those of their noncarrier counterparts.

Conclusions: In this Northern Chinese Han population, the Adrs266729 and rs2241766 G alleles were closely associated with the occurrence of NAFLD. However, only NAFLD patients who carried the Adrs266729 G allele had an increased risk of developing CAD.
\end{abstract}

Keywords: Adiponectin, Polymorphisms, Genetic, Nonalcoholic Fatty Liver Disease, Coronary Artery Disease

\section{Background}

Nonalcoholic fatty liver disease (NAFLD) is the most common and prevalent liver disease worldwide (1), the prevalence of the global has reached $25.24 \%$ (22.10 - 28.65) (2). Accumulated evidence suggests that coronary artery disease (CAD) is closely related to the severity and progression of NAFLD, and it is the leading cause of mortality in NAFLD (3). Adams et al. (4) showed that cardiovascular disease accounted for about $25 \%$ of deaths in patients with NAFLD versus $13 \%$ of deaths in those with other liver diseases. Adiponectin (Ad), a 30-kDa peptide hormone, is almost exclusively secreted by adipose tissue (5). The human
Ad gene is located on chromosome $3 q 27$, containing three exons and two introns and encoding 244 amino acids (6). Recently, several single-nucleotide polymorphisms of the Ad gene, such as rs266729 (C > G) and rs2241766 ( $>$ > G), were shown to be significantly associated with (6). As one of the most abundant fat-derived biologically active proteins $(7,8)$, Ad plays an important role in the regulation of lipid metabolism and glucose metabolism, especially in improving insulin sensitivity, which is a key factor in the pathogenesis of NAFLD. Previous studies revealed a strong association between the presence of Ad polymorphisms and the risk of developing NAFLD, especially in patients of Chinese origin (9-16). The role of Ad polymorphisms

Copyright (c) 2016, Kowsar Corp. This is an open-access article distributed under the terms of the Creative Commons Attribution-NonCommercial 4.0 International License (http://creativecommons.org/licenses/by-nc/4.0/) which permits copy and redistribute the material just in noncommercial usages, provided the original work is properly cited. 
in the susceptibility to CAD has been widely studied, but the results are inconsistent (17-19). Considering the high prevalence of CAD-related mortality in NAFLD patients (3), identifying the potential association between Ad polymorphisms and the relative risk of developing CAD in NAFLD patients is extremely important.

\section{Objectives}

In the present study, we selected and genotyped two Ad gene polymorphisms, rs266729 (C > G) and rs2241766 ( $\mathrm{T}>$ $\mathrm{G})$, in NAFLD patients, with or without CAD and in healthy controls. We then investigated the association of these two Ad polymorphisms with the risk of developing CAD among NAFLD patients in a Chinese Han population.

\section{Materials and Methods}

\subsection{Study Subjects}

This case-control study was approved by the ethics committee on human research of Qingdao municipal hospital (Qingdao, China). Written informed consent was obtained from each subject prior to starting the study, and all the subjects in the study were of Northern Han Chinese origin. This study was performed in accordance with the principles of the declaration of Helsinki and its appendices (20).

From April 2010 to May 2015, we selected 493 unrelated adult Chinese patients of both genders who had been diagnosed with NAFLD using B-type ultrasonography. Of those, 246 had CAD (127 males, 118 females, mean age of $61.54 \pm$ 10.28 years), and 247 did not have CAD (126 males, 120 females, mean age of $62.13 \pm 9.74$ years). We also selected 304 healthy sex- and age-matched controls (152 males, 152 females, mean age of $61.31 \pm 9.40$ years). Data on the patients and healthy controls were collected from the department of gastroenterology and cardiology of Qingdao municipal hospital. NAFLD was diagnosed by a standard clinical evaluation, according to the criteria of the AASID (21). The diagnosis of CAD was based on a percutaneous coronary angiogram, which was evaluated by two experienced interventional cardiologists. CAD was defined as the presence of at least $50 \%$ stenosis in at least one of the coronary arteries. The control volunteers were confirmed as being healthy by echocardiography, medical history, and general and laboratory examinations at the same hospital. Subjects who had cardiac disorders, other liver diseases, infectious disease, diabetes mellitus, concurrent major renal disease, or a history of medication were excluded.

\subsection{Baseline Demographic and Biochemical Analyses}

We used a standard study questionnaire to obtain basic clinicopathological information (name, age, gender, height, weight, smoker, hypertension). The body mass index (BMI) was calculated using the following equation: $\mathrm{BMI}=$ weight $/$ height $^{2}\left(\mathrm{~kg} / \mathrm{m}^{2}\right)(22)$.

After a 12-hour overnight fast, blood samples were collected from each subject in ethylene diamine tetraacetic acid-containing tubes. Serum alanine aminotransferase (ALT), aspartate aminotransferase (AST), triglyceride (TG), total cholesterol (TC), fasting plasma glucose (FPG), highdensity lipoprotein (HDL) ,and low-density lipoprotein (LDL) were measured using routine enzymatic methods (23). The concentration of total Ad was obtained by a radioimmunoassay, using a human Ad RIA kit.

\subsection{Genomic DNA Extraction and Genotyping}

Genomic DNA was extracted using a genomic DNA purification kit (Beijing Bioteke biotechnology, Beijing, China) for peripheral blood, according to the manufacturer's instructions and stored at $-20^{\circ} \mathrm{C}$ until use. The primers for PCR amplification of the fragments containing rs266729 and rs2241766 were synthesized by Shanghai Sangon Biotech company: Ad 5'-CAGACACTTGCCCTGCCTCTGT3' and 5'-TGGCAACATTCAACACCTTGGA-3' for rs266729; 5'-ACATGTGGATTCCAGGGCTCAG-3' and 5'CTTCTCACCAGGGGTGCCATCT-3' for rs2241766. The PCR amplification profile was as follows: predenaturation at $94^{\circ} \mathrm{C}$ for 5 minutes, 35 cycles, denaturation at $94^{\circ} \mathrm{C}$ for 20 seconds, annealing at $62^{\circ} \mathrm{C}$ for 30 seconds, extending at $72^{\circ} \mathrm{C}$ for 30 seconds, and finally extending at $72^{\circ} \mathrm{C}$ for 5 minutes to terminate the reaction. Target amplified fragments were then detected by gel electrophoresis in $2 \%$ gel with a 197-base and 218-base pair product, respectively. The Ad genotypes were detected by direct DNA sequencing using the ABI Prism sequence detection system ABI3730 (Foster City, CA, USA).

\subsection{Statistical Analysis}

Differences in characteristics of the different groups were analyzed using the Student's test or the $\chi^{2}$ test. Baseline characteristics are expressed as the mean \pm standard deviation (S.D.), and categorical data are presented as percentages and numbers. The quantitative variables were distributed normally. Genotype and allele frequencies were assessed by counting the DNA sequencing data of each subject. Differences in the distributions of the patients versus those of the controls were analyzed by Pearson's $\chi^{2}$ test or Fisher's exact test, where appropriate. The Hardy-Weinberg equilibrium between expected 
and observed genotype distributions was estimated using the $\chi^{2}$ test. Logistic regression analysis was used to evaluate the association between the polymorphisms and presence/absence of CAD. The association was also determined by estimating the odds ratios (ORs), with their 95\% confidence intervals (CIs). These statistical analyses were performed using SPSS 17.0 statistical software (SPSS Inc., Chicago, IL, USA). All P values of less than 0.05 were considered statistically significant.

\section{Results}

\subsection{Characteristics of the Study Participants}

The baseline characteristics of the three groups (NAFLD with CAD, NAFLD without CAD, and healthy controls) according to the experimental requirements are shown in Table1. There were no significant age, gender, or height differences between the three groups $(\mathrm{P}>0.05)$. The prevalence of the weight, increased BMI, hypertension, serum ALT and AST levels, serum TG, TC, and LDL levels, FPG, decreased HDL and Ad levels in NAFLD subjects (with and without CAD) were significantly higher than in the controls $(\mathrm{P}<0.05)$.

Importantly, NAFLD patients with CAD had a higher prevalence of smoking and hypertension, increased weight, BMI, ALT, AST, TG, TC, FPG, and LDL, decreased HDL levels and Ad levels compared to the healthy controls (all $\mathrm{P}<0.05)$. In the NAFLD patients without CAD, we found an increased prevalence of smoking and hypertension, higher TG and LDL levels, and lower HDL and Ad levels compared to those with $\mathrm{CAD}$ (all $\mathrm{P}<0.05)$.

\subsection{Ad rs266729 and rs2241766 Genotype and Allele Distribu- tion}

The genotype distributions of Adrs266729 and rs2241766 were correlated with the Hardy-Weinberg equilibrium in both the patients and controls (all P> 0.05) (Table 2). As shown in Table 3, there was a significant difference in the genotypic and allelic distributions of the NAFLD patients and their control counterparts (OR: 0.414, 95\% CI: 0.291 0.590, P < 0.001; OR: 0.610, 95\% CI: 0427 - 0.873, P = 0.007; OR: $0.473,95 \%$ CI: $0.353-0.633, \mathrm{P}<0.001$, OR: $0.633,95 \%$ CI: $0.468-0.855, \mathrm{P}=0.003$, respectively) at position $\mathrm{Ad}$ rs266729. Moreover, there was a statistically significant difference at position Ad rs266729 between the NAFLD patients with CAD versus those without CAD (OR: 0.679, 95\% CI: 0.474 - 0.970, P = 0.033; OR: 0.747, 95\% CI: 0.561 - 0.994, P $=0.045$, respectively) At position Ad rs2241766, there was a strongly statistical difference observed between the NAFLD patients and their control counterparts (OR: 0.675, 95\% CI: 0.481-0.949, P = 0.023; OR: 0.681, 95\% CI: 0.485 - 0.956, $\mathrm{P}=$ 0.026; OR: 0.730, 95\% CI: 0.557 - 0.956, P= 0.022, OR: 0.720,
95\% CI: $0.549-0.943, \mathrm{P}=0.017$, respectively). Nevertheless, there was no statistically significant difference in the $\mathrm{Ad}$ rs2241766 polymorphism between the NAFLD patients with CAD and without CAD ( $\mathrm{P}=0.965$ and 0.921, respectively).

\subsection{Association of the Ad Polymorphisms with Clinical Param- eters in NAFLD Patients}

We compared the Ad rs266729 and rs2241766 genotypes with the clinical characteristics of the NAFLD patients, with or without CAD and the control group to estimate whether the rs266729 and rs2241766 gene polymorphisms were correlated with clinical parameters (Table 4 ). With regard to position rs266729, the serum TG, TC, FPG, and LDL levels of the NAFLD CAD patients with a CG+GG genotype were significantly higher than those with a CC genotype ( $\mathrm{P}=$ 0.031, $\mathrm{P}=0.034, \mathrm{P}=0.007$, and $\mathrm{P}<0.001$, respectively). With regard to Ad rs266729(CG+GG) the genotype of NAFLD patients with CAD showed lower Ad levels in serum than those with the CC genotype $(\mathrm{P}<0.001)$. Furthermore, CADfree NAFLD patients with the rs266729 (CG+GG) genotype exhibited higher TG and serum FPG levels and lower serum Ad levels than those with the CC genotype $(\mathrm{P}=0.014, \mathrm{P}$ $=0.038$, and $\mathrm{P}<0.001$, respectively). In both the NAFLD groups, the serum TG levels of those with the rs2241766 GT+GG genotype were higher than those with the $r s 2241766$ TT genotype ( $\mathrm{P}=0.039$ and $\mathrm{P}=0.042$, respectively). No other statistically significant differences were observed between the controls, with regards to the presence of the rs2241766 gene polymorphism $(\mathrm{P}>0.05)$.

\section{Discussion}

In this study, we correlated the expression of the $\mathrm{Ad}$ rs266729 and rs2241766 gene polymorphisms with the risk of developing CAD in NAFLD patients for the first time. The main finding of our study was that the Ad rs266729 G allele and rs2241766 G allele were significantly associated with the occurrence of NAFLD. In addition, the NAFLD patients in this Northern Han Chinese population who carried the Ad rs266729 G allele had an increased risk of developing CAD. Future studies are required to determine whether and how this polymorphism modulates Ad expression, as well as the role of the Ad polymorphism in the pathogenesis of CAD in the setting of NAFLD.

The Ad gene, which is expressed primarily in adipose and vascular tissues, encodes the protein Ad (24). Ad has been shown to have anti-inflammatory effects and antiatherosclerotic properties (25) and to have important roles in insulin sensitivity $(7,8)$. Overexpression of Ad may contribute to the development of NAFLD, atherosclerosis, 
Table 1. Baseline Characteristics of the Study Participants ${ }^{\mathrm{a}}$

\begin{tabular}{|c|c|c|c|c|c|c|}
\hline \multirow[t]{2}{*}{ Characteristics } & \multicolumn{3}{|c|}{ Groups } & \multicolumn{3}{|c|}{ PValue } \\
\hline & CAD+NAFLD $(n=246)$ & CAD-NAFLD $(n=247)$ & Control $(n=304)$ & P1 & $\mathbf{P 2}$ & P3 \\
\hline Age, $y$ & $61.54 \pm 10.28$ & $62.13 \pm 9.74$ & $61.31 \pm 9.40$ & 0.514 & 0.782 & 0.316 \\
\hline Gender, Female/Male & $119 / 127$ & $121 / 126$ & $152 / 152$ & 0.991 & 0.491 & 0.518 \\
\hline Height, m & $1.68 \pm 0.07$ & $1.68 \pm 0.03$ & $1.67 \pm 0.08$ & 1.032 & 1.342 & 0.782 \\
\hline Weight, kg & $67.46 \pm 7.31$ & $67.32 \pm 7.42$ & $66.54 \pm 6.41$ & 0.602 & 0.007 & 0.003 \\
\hline Smoker, No. (\%) & $115(46.7)$ & $90(36.4)$ & $100(32.9)$ & 0.02 & 0.001 & 0.384 \\
\hline BMI, $\mathrm{Kg} / \mathrm{m}^{2}$ & $25.83 \pm 3.20$ & $26.05 \pm 3.36$ & $23.13 \pm 2.96$ & 0.457 & $<0.001$ & $<0.001$ \\
\hline Hypertension, No. (\%) & $125(50.8)$ & $99(40.1)$ & $68(22.4)$ & 0.017 & $<0.001$ & $<0.001$ \\
\hline ALT, $\mathbf{U} / \mathbf{L}$ & $41.88 \pm 23.80$ & $42.09 \pm 23.12$ & $20.75 \pm 9.63$ & 0.92 & $<0.001$ & $<0.001$ \\
\hline AST, $\mathbf{U} / \mathbf{L}$ & $40.57 \pm 22.01$ & $41.49 \pm 22.39$ & $20.33 \pm 8.13$ & 0.647 & $<0.001$ & $<0.001$ \\
\hline $\mathrm{TG}, \mathrm{mmol} / \mathrm{L}$ & $2.34 \pm 0.99$ & $1.88 \pm 0.81$ & $1.35 \pm 0.58$ & $<0.001$ & $<0.001$ & $<0.001$ \\
\hline $\mathrm{TC}, \mathbf{m m o l} / \mathbf{L}$ & $5.22 \pm 0.96$ & $5.05 \pm 0.94$ & $4.32 \pm 0.93$ & 0.057 & $<0.001$ & $<0.001$ \\
\hline FPG, $\mathrm{mmol} / \mathrm{L}$ & $5.32 \pm 0.83$ & $5.07 \pm 0.53$ & $4.93 \pm 0.49$ & 0.624 & $<0.001$ & $<0.001$ \\
\hline HDL, mmol/L & $1.21 \pm 0.38$ & $1.36 \pm 0.41$ & $1.56 \pm 0.42$ & $<0.001$ & $<0.001$ & $<0.001$ \\
\hline LDL, $\mathbf{m m o l} / \mathbf{L}$ & $2.90 \pm 0.86$ & $2.70 \pm 0.86$ & $2.61 \pm 0.75$ & 0.011 & $<0.001$ & 0.021 \\
\hline Adiponectin, ug/mL & $12.63 \pm 2.83$ & $15.31 \pm 3.72$ & $19.32 \pm 3.21$ & $<0.001$ & $<0.001$ & $<0.001$ \\
\hline
\end{tabular}

Abbreviations: CAD+NAFLD, nonalcoholic fatty liver disease patients with coronary artery disease; CAD-NAFLD, NALFD patients without CAD; BMI, body mass index; ALT, alanine aminotransferase; AST, aspartate aminotransferase; TG, triglycerides; TC, total cholesterol; FPG, fasting plasma glucose; HDL, high-density lipoprotein; LDL, lowdensity lipoprotein; P1, CAD+NAFLD vs. CAD-NAFLD; P2, CAD+NAFLD vs. control; P3, CAD-NAFLD vs. control.

${ }^{\mathrm{a}}$ Values are expressed as mean $\pm \mathrm{SD}$ unless otherwise indicated.

Table 2. Results of the Hardy-Weinberg Equilibrium

\begin{tabular}{ccc}
\hline Gene Locus Groups & $\chi^{2}$ & P \\
\hline rs266729 & & \\
CAD+NAFLD & 0.314 & 0.575 \\
CAD-NAFLD & 3.017 & 0.082 \\
Controls & 3.324 & 0.068 \\
\hline $\mathbf{r s 2 2 4 1 7 6 6}$ & & \\
\hline CAD+NAFLD & 0.813 & 0.367 \\
CAD-NAFLD & 1.829 & 0.176 \\
Controls & 3.310 & 0.069 \\
\hline
\end{tabular}

and CAD by affecting the metabolism of major lipids, reducing insulin receptor signaling, and blocking insulin actions $(16,26,27)$. Hashemi et al. (28) reported that the prevalence of Adrs266729 in Iranian patients with NAFLD was higher than that of controls. Similar findings were reported in some Chinese populations (16). Our results also showed that the frequency of the Ad rs266729 G allele was higher in the NAFLD groups than in the control group. Moreover, the Ad polymorphism at position rs266729 G al- lele increased TG, TC, and LDL levels in patients with NAFLD. These results are consistent with other Chinese data (16). In addition, the serum Ad level was decreased in those with the G allele and the Ad polymorphism at position rs266729. In common with the findings of the preset study, Wang et al. (29) reported that variant alleles at rs266729 were associated with lower Ad levels.

Although the results indicate that the G allele of $\mathrm{Ad}$ rs266729 may contribute to the development of NAFLD, there is no consensus on whether rs2241766 is a risk factor for the prevalence of NAFLD. Tokushige et al. (30) discovered that the Ad rs2241766 genotype GG was related to the progression of NAFLD in Japanese patients. However, Wang et al. (31) revealed that this genotype was not significantly associated with NAFLD in a Southern Han Chinese population. Interestingly, in the current study, we found that Ad rs2241766 was associated with NAFLD in a Northern Han Chinese population. However, further studies with larger samples and different ethnicities or races are needed to confirm the findings (27).

CAD is a multifactorial disorder. The results of previous studies on the association between Ad gene polymorphisms and the risk of CAD are conflicting. One study of a Northeast Han Chinese population showed that the pres- 
Table 3. Distribution of the Adiponectin rs266729 and rs2241766 Polymorphisms in the Study Groups ${ }^{\mathrm{a}}$

\begin{tabular}{|c|c|c|c|c|c|c|c|c|c|c|c|c|}
\hline Genotype & CAD+NAFLD & CAD-NAFLD & Controls & $\mathrm{OR}(95 \% \mathrm{CI})$ & $\chi^{2}$ & P1 & OR $(95 \% \mathrm{CI})$ & $\chi^{2}$ & P2 & OR $(95 \% \mathrm{CI})$ & $\chi^{2}$ & P3 \\
\hline \multicolumn{13}{|l|}{ rs266729 } \\
\hline CC & $127(51.6)$ & $151(61.1)$ & $219(72.0)$ & & & & & & & & & \\
\hline $\mathrm{GG}+\mathrm{GC}$ & $119(48.4)$ & $96(38.9)$ & $85(28.0)$ & $0.679(0.474-0.970)$ & 4.530 & 0.033 & $0.414(0.291-0.590)$ & 24.283 & $<0.001$ & $0.610(0.427-0.873)$ & 7.348 & 0.007 \\
\hline Allele C & $351(71.3)$ & $380(76.9)$ & $511(84.0)$ & & & & & & & & & \\
\hline Allele G & $141(28.7)$ & $114(23.1)$ & $97(16.0)$ & $0.747(0.561-0.994)$ & 4.005 & 0.045 & $0.473(0.353-0.633)$ & 25.888 & $<0.001$ & $0.633(0.468-0.855)$ & 8.933 & 0.003 \\
\hline \multicolumn{13}{|l|}{ rs2241766 } \\
\hline TT & $126(51.2)$ & $127(51.4)$ & $185(60.9)$ & & & & & & & & & \\
\hline $\mathrm{GG}+\mathrm{GT}$ & $120(48.8)$ & $120(48.6)$ & $119(39.4)$ & $0.992(0.697-1.412)$ & 0.002 & 0.965 & $0.675(0.481-0.949)$ & 5.138 & 0.023 & $0.681(0.485-0.956)$ & 4.943 & 0.026 \\
\hline Allele T & $348(70.7)$ & $348(70.4)$ & $467(76.8)$ & & & & & & & & & \\
\hline Allele G & $144(29.3)$ & $146(29.6)$ & $141(23.2)$ & $1.014(0.771-1.333)$ & 0.010 & 0.921 & $0.730(0.557-0.956)$ & 5.233 & 0.022 & $0.720(0.549-0.943)$ & 5.731 & 0.017 \\
\hline
\end{tabular}

Abbreviations: CAD+NAFLD, nonalcoholic fatty liver disease patients with coronary artery disease; CAD-NAFLD, NAFLD patients without CAD; P1, CAD+NAFLD vs. CAD-NAFLD; P2, CAD+NAFLD vs. control; P3, CAD-NAFLD vs. control. ${ }^{\mathrm{a}}$ Values are expressed as mean $\pm \mathrm{SD}$.

ence of the Ad rs2082940 variant was significantly associated with CAD (7). Specifically, these investigators found that the Ad rs2082940 G allele seemed to protect against the progression of CAD. On the other hand, Tong et al. (17) found that the presence of the G allele of the rs266729 was strongly correlated with an increased prevalence of CAD in Europeans. Hoefle et al. (32) reached the same conclusion in a study of an Australian population. A recent metaanalysis concluded that there was a strong association between Ad rs266729 and cardiovascular disease (33). In agreement with previous studies, Foucan et al. (34) showed that French patients carrying the Ad rs2241766 G allele had an increased risk of CAD. Other studies have reported discordant findings because of differences in ethnicity, phenotypes, and environments $(16,33)$. In the present study, the frequency of the Ad rs266729 G allele in NAFLD patients with CAD was substantially higher than in those without CAD. In addition, NAFLD patients with CAD who carried the Ad rs266729 G allele had increased serum TG, TC, and LDL levels compared to those who did not carry the $\mathrm{G}$ allele. The Ad rs2241766 polymorphism was not associated with the risk of developing CAD, but it had detrimental effects on lipid levels in NAFLD patients with CAD, indicating that the Ad G allele could lead to insulin resistance in CAD patients and that it may increase the risk of cardiovascular complications. Several previous studies showed that high concentrations of serum Ad decreased the risk of CAD in male diabetic patients (35), the risk of myocardial infarction in healthy men (36), and cardiovascular disease outcomes in patients with end-stage renal failure (37). In addition, Ad increased the production of endothelial NO, which has well-documented antithrombotic, antiatherogenic, and vasodilatory actions $(38,39)$. Thus, the literature demonstrates that Ad may have potential benefits in the treatment and prevention of cardiovascular disease (40). Further studies are needed to associate the Ad single- nucleotide polymorphism with expression of the Ad protein.

Some limitations of our study should be acknowledged. First, the entire study population was racially homogeneous, and the participants were all Han. Moreover, the population was highly selected. Therefore, our results may not be applicable to other populations. Second, we used ultrasonography to diagnose NAFLD because of the difficulty in obtaining a liver biopsy. Third, our study did not correlate Ad polymorphisms with the level of expression and insulin resistance or disease severity in NAFLD patients. Finally, larger sample sizes and diverse ethnic groups are needed in future studies to confirm the present data.

In conclusion, we found that the presence of the $\mathrm{Ad}$ rs266729 $\mathrm{G}$ allele increased the risk of CAD in NAFLD patients. The Ad rs2241766 G allele may a risk factor for the development of NAFLD but not CAD in these patients. Additional studies are needed to delineate the mechanisms underlying the potential roles of these Ad gene polymorphisms in the risk of CAD in NAFLD.

\section{Footnotes}

Authors' Contribution: Study concept and design, ShuiXian Du, Lin-Lin Lu; acquisition of the data, Shui-Xian Du and Yang Liu; analysis and interpretation of the data, ShuiXian Du; drafting of the manuscript, Shui-Xian Du and Lin-Lin Lu; critical revision of the manuscript for important intellectual content, Shi-Ying Xuan and Yong-Ning Xin; statistical analysis, Shui-Xian Du, Yang Liu, and Lin-Lin Lu; administrative, technical, and material support; YongNing Xin and Quan-Jiang Dong; study supervision, Shi-Ying Xuan and Yong-Ning Xin.

Funding/Support: This study was supported by the Qingdao Livelihood, science and technology project, China 
(Grant No.14-2-3-17-nsh) and Qingdao key health discipline development fund.

\section{References}

1. Kim S, Hong J, Jeon R, Kim HS. Adzuki bean ameliorates hepatic lipogenesis and proinflammatory mediator expression in mice fed a high-cholesterol and high-fat diet to induce nonalcoholic fatty liver disease. Nutr Res. 2016;36(1):90-100. doi: 10.1016/j.nutres.2015.11.002. [PubMed: 26773785].

2. Rinella $M$, Charlton M. The globalization of nonalcoholic fatty liver disease: Prevalence and impact on world health. Hepatology. 2016;64(1):19-22. doi: 10.1002/hep.28524. [PubMed: 26926530].

3. Vilar CP, Cotrim HP, Florentino GS, Bragagnoli G, Schwingel PA, Barreto $\mathrm{CP}$. Nonalcoholic fatty liver disease in patients with coronary disease from a Brazil northeast area. Arq Gastroenterol. 2015;52(2):111-6. doi: 10.1590/S0004-28032015000200007. [PubMed: 26039828].

4. Adams LA, Lymp JF, St Sauver J, Sanderson SO, Lindor KD, Feldstein A, et al. The natural history of nonalcoholic fatty liver disease: a population-based cohort study. Gastroenterology. 2005;129(1):113-21. [PubMed: 16012941].

5. Wiecek A, Adamczak M, Chudek J. Adiponectin-an adipokine with unique metabolic properties. Nephrol Dial Transplant. 2007;22(4):9818. doi: 10.1093/ndt/gfl814. [PubMed: 17234664].

6. Jee SH, Sull JW, Lee JE, Shin C, Park J, Kimm H, et al. Adiponectin concentrations: a genome-wide association study. Am J Hum Genet. 2010;87(4):545-52. doi: 10.1016/j.ajhg.2010.09.004. [PubMed: 20887962].

7. Yamauchi T, Kamon J, Waki H, Terauchi Y, Kubota N, Hara K, et al. The fat-derived hormone adiponectin reverses insulin resistance associated with both lipoatrophy and obesity. Nat Med. 2001;7(8):941-6. doi: 10.1038/90984. [PubMed: 11479627].

8. Berg AH, Combs TP, Du X, Brownlee M, Scherer PE. The adipocytesecreted protein Acrp30 enhances hepatic insulin action. Nat Med. 2001;7(8):947-53. doi: 10.1038/90992. [PubMed: 11479628].

9. Abenavoli L, D. I. Renzo L, Guzzi PH, Pellicano R, Milic N, D. E. Lorenzo A . Non-alcoholic fatty liver disease severity, central fat mass and adinopectin: a close relationship. Clujul Med. 2015;88(4):489-93. doi: 10.15386/cjmed-595. [PubMed: 26733747].

10. Stojsavljevic S, Gomercic Palcic M, Virovic Jukic L, Smircic Duvnjak L, Duvnjak M. Adipokines and proinflammatory cytokines, the key mediators in the pathogenesis of nonalcoholic fatty liver disease. World J Gastroenterol. 2014;20(48):18070-91. doi: 10.3748/wjg.v20.i48.18070. [PubMed: 25561778]

11. Abenavoli L, Peta V. Role of adipokines and cytokines in non-alcoholic fatty liver disease. Rev Recent Clin Trials. 2014;9(3):134-40. [PubMed: 25514909].

12. Giby VG, Ajith TA. Role of adipokines and peroxisome proliferatoractivated receptors in nonalcoholic fatty liver disease. World J Hepatol. 2014;6(8):570-9. doi: 10.4254/wjh.v6.i8.570. [PubMed: 25232450].

13. Li HJ, Li CP, Zhang C, Zhong XL, Shi L. Association of Adiponectin gene polymorphisms and nonalcoholic fatty liver disease. Int J Clin Exp Med. 2015;8(9):16676-81. [PubMed: 26629202].

14. Zhang C, Guo L. [Correlation of polymorphisms of adiponectin receptor 2 gene $+33371 \mathrm{Gln} / \mathrm{Arg}$, cytochrome P4502E1 gene Rsa I and smoking with nonalcoholic fatty liver disease]. Nan Fang Yi Ke Da Xue Xue Bao. 2014;34(10):1481-7. [PubMed: 25345946].

15. Zhou YJ, Zhang ZS, Nie YQ, Cao J, Cao CY, Li YY. Association of adiponectin gene variation with progression of nonalcoholic fatty liver disease: A 4-year follow-up survey.J Dig Dis. 2015;16(10):601-9. doi: 10.1111/1751-2980.12288. [PubMed: 26334200].

16. Wang BF, Wang Y, Ao R, Tong J, Wang BY. AdipoQ T45 G and G276 T Polymorphisms and Susceptibility to Nonalcoholic Fatty Liver Disease Among Asian Populations: A Meta-Analysis and Meta-Regression.
J Clin Lab Anal. 2016;30(1):47-57. doi: 10.1002/jcla.21814. [PubMed: 25385252].

17. Tong G, Wang N, Leng J, Tong X, Shen Y, Yang J, et al. Common variants in adiponectin gene are associated with coronary artery disease and angiographical severity of coronary atherosclerosis in type 2 diabetes. Cardiovasc Diabetol. 2013;12:67. doi:10.1186/1475-2840-12-67. [PubMed: 23590551].

18. Yang Y, Zhang F, Ding R, Wang Y, Lei H, Hu D. Association of ADIPOQ gene polymorphisms and coronary artery disease risk: a metaanalysis based on 12465 subjects. Thromb Res. 2012;130(1):58-64. doi: 10.1016/j.thromres.2012.01.018. [PubMed: 22386722].

19. Zhang B, Peng W, Li H, Lu Y, Zhuang J, Wang K, et al. Plasma vaspin concentrations are decreased in acute coronary syndrome, but unchanged in patients without coronary lesions. Clin Biochem. 2013;46(15):1520-5. doi: 10.1016/j.clinbiochem.2013.06.028. [PubMed: 23850850]

20. Rickham PP. Human Experimentation. Code of Ethics of the World Medical Association. Declaration of Helsinki. $\mathrm{Br}$ Med J 1964;2(5402):177. [PubMed: 14150898].

21. Jian-gao F, Chinese Liver Disease A. Guidelines for management of nonalcoholic fatty liver disease: an updated and revised edition. Zhonghua Gan Zang Bing Za Zhi. 2010;18(3):163-6. [PubMed: 20698076].

22. Lee Y, Kim BK, Lim YH, Kim MK, Choi BY, Shin J. The relationship between adiponectin and left ventricular mass index varies with the risk of left ventricular hypertrophy. PLoS One. 2013;8(7):eee70246. doi: 10.1371/journal.pone.0070246. [PubMed: 23894624].

23. Kotronen A, Westerbacka J, Bergholm R, Pietilainen KH, Yki-Jarvinen H. Liver fat in the metabolic syndrome. J Clin Endocrinol Metab. 2007;92(9):3490-7. doi: 10.1210/jc.2007-0482. [PubMed: 17595248].

24. Hermann TS, Li W, Dominguez H, Ihlemann N, Rask-Madsen C, MajorPedersen A, et al. Quinapril treatment increases insulin-stimulated endothelial function and adiponectin gene expression in patients with type 2 diabetes. J Clin Endocrinol Metab. 2006;91(3):1001-8. doi: 10.1210/jc.2005-1231. [PubMed: 16352688].

25. Funahashi T, Nakamura T, Shimomura I, Maeda K, Kuriyama $\mathrm{H}$, Takahashi M, et al. Role of adipocytokines on the pathogenesis of atherosclerosis in visceral obesity. Intern Med. 1999;38(2):202-6 [PubMed: 10225688].

26. Handa P, Maliken BD, Nelson JE, Morgan-Stevenson V, Messner DJ, Dhillon BK, et al. Reduced adiponectin signaling due to weight gain results in nonalcoholic steatohepatitis through impaired mitochondrial biogenesis. Hepatology. 2014;60(1):133-45. doi: 10.1002/hep.26946. [PubMed: 24464605].

27. Kanu JS, Gu Y, Zhi S, Yu M, Lu Y, Cong Y, et al. Single nucleotide poly morphism rs3774261 in the AdipoQ gene is associated with the risk of coronary heart disease (CHD) in Northeast Han Chinese population: a case-control study. Lipids Health Dis. 2016;15:6. doi: 10.1186/s12944-0150173-4. [PubMed: 26754433].

28. Hashemi M, Hanafi Bojd H, Eskandari Nasab E, Bahari A, Hashemzehi NA, Shafieipour S, et al. Association of Adiponectin rs1501299 and rs266729 Gene Polymorphisms With Nonalcoholic Fatty Liver Disease. Hepat Mon. 2013;13(5):eee9527. doi: 10.5812/hepatmon.9527. [PubMed: 23922565].

29. Wang X, Zhang S, Chen Y, Liu H, Lan C, Chen X, et al. APM1 gene variants $-11377 \mathrm{C} / \mathrm{G}$ and $4545 \mathrm{G} / \mathrm{C}$ are associated respectively with obesity and with non-obesity in Chinese type 2 diabetes. Diabetes Res Clin Pract. 2009;84(3):205-10. doi: 10.1016/j.diabres.2009.03.004 [PubMed: 19359061].

30. Tokushige K, Hashimoto E, Noto H, Yatsuji S, Taniai M, Torii N, et al Influence of adiponectin gene polymorphisms in Japanese patients with non-alcoholic fatty liver disease.J Gastroenterol. 2009;44(9):97682. doi: 10.1007/s00535-009-0085-z. [PubMed: 19484180].

31. Wang ZL, Xia B, Shrestha U, Jiang L, Ma CW, Chen Q, et al. Correlation between adiponectin polymorphisms and non-alcoholic fatty liver disease with or without metabolic syndrome in Chinese popula- 
tion.J Endocrinol Invest. 2008;31(12):1086-91. doi: 10.1007/BF03345657. [PubMed: 19246975].

32. Hoefle G, Muendlein A, Saely CH, Risch L, Rein P, Koch L, et al. The -11377 $\mathrm{C}>\mathrm{G}$ promoter variant of the adiponectin gene, prevalence of coronary atherosclerosis, and incidence of vascular events in men. Thromb Haemost. 2007;97(3):451-7. [PubMed:17334513].

33. Zhang H, Mo X, Hao Y, Gu D. Association between polymorphisms in the adiponectin gene and cardiovascular disease: a meta-analysis. BMC Med Genet. 2012;13:40. doi: 10.1186/1471-2350-13-40. [PubMed: 22639977].

34. Foucan L, Maimaitiming S, Larifla L, Hedreville S, Deloumeaux J, Joannes MO, et al. Adiponectin gene variants, adiponectin isoforms and cardiometabolic risk in type 2 diabetic patients. J Diabetes Investig. 2014;5(2):192-8. doi: 10.1111/jdi.12133. [PubMed: 24843760].

35. Schulze MB, Shai I, Rimm EB, Li T, Rifai N, Hu FB. Adiponectin and future coronary heart disease events among men with type 2 diabetes. Diabetes. 2005;54(2):534-9. [PubMed: 15677512].

36. Pischon T, Girman CJ, Hotamisligil GS, Rifai N, Hu FB, Rimm EB.
Plasma adiponectin levels and risk of myocardial infarction in men. JAMA. 2004;291(14):1730-7. doi: 10.1001/jama.291.14.1730. [PubMed: 15082700].

37. Zoccali C, Mallamaci F, Tripepi G, Benedetto FA, Cutrupi S, Parlongo $\mathrm{S}$, et al. Adiponectin, metabolic risk factors, and cardiovascular events among patients with end-stage renal disease. J Am Soc Nephrol. 2002;13(1):134-41. [PubMed: 11752030].

38. Ouchi N, Ohishi M, Kihara S, Funahashi T, Nakamura T, Nagaretani $\mathrm{H}$, et al. Association of hypoadiponectinemia with impaired vasoreactivity. Hypertension. 2003;42(3):231-4. doi: 10.1161/01.HYP.0000083488.67550.B8. [PubMed:12860835].

39. Hattori Y, Suzuki M, Hattori S, Kasai K. Globular adiponectin upregulates nitric oxide production in vascular endothelial cells. Diabetologia. 2003;46(11):1543-9. doi: 10.1007/s00125-003-1224-3. [PubMed: 14551684].

40. Lopez-Jaramillo P. The Role of Adiponectin in Cardiometabolic Diseases: Effects of Nutritional Interventions. J Nutr. 2016;146(2):422S-6S. doi: 10.3945/jn.114.202432. [PubMed: 26764331]. 
Table 4. Comparison of Adiponectin rs266729 and rs2241766 Genotypes With Clinicopathological Parameters ${ }^{\mathrm{a}}$

\begin{tabular}{|c|c|c|c|c|}
\hline \multirow[t]{2}{*}{ Parameters } & \multicolumn{2}{|c|}{ rs266729 } & \multicolumn{2}{|c|}{ rs2241766 } \\
\hline & $\mathbf{G C}+\mathbf{G G}$ & CC & $\mathbf{G G}+\mathbf{G T}$ & TT \\
\hline CAD+NAFLD & $\mathrm{N}=119$ & $\mathrm{~N}=127$ & $\mathrm{~N}=120$ & $\mathrm{~N}=126$ \\
\hline Age, $y$ & $46.54 \pm 11.04$ & $46.39 \pm 12.08$ & $46.39 \pm 11.21$ & $45.94 \pm 11.09$ \\
\hline Gender, Female/Male & $57 / 62$ & $62 / 65$ & $59 / 61$ & $60 / 66$ \\
\hline Weight, kg & $67.53 \pm 6.31$ & $65.98 \pm 7.02$ & $68.21 \pm 5.98$ & $67.34 \pm 6.56$ \\
\hline Smoker, No. (\%) & $67(56.30)$ & $61(48.03)$ & $58(48.3)$ & $63(50.0)$ \\
\hline $\mathrm{BMI}, \mathrm{kg} / \mathrm{m}^{2}$ & $24.29 \pm 3.76$ & $25.31 \pm 3.32$ & $23.67 \pm 4.62$ & $24.54 \pm 3.21$ \\
\hline Hypertension, No. (\%) & $60(50.4)$ & $61(48.0)$ & $58(48.3)$ & $60(47.6)$ \\
\hline ALT, U/L & $44.52 \pm 21.43$ & $43.62 \pm 22.36$ & $44.31 \pm 21.54$ & $43.96 \pm 21.09$ \\
\hline AST, U/L & $41.34 \pm 20.31$ & $40.56 \pm 21.09$ & $40.99 \pm 21.23$ & $39.62 \pm 20.97$ \\
\hline $\mathrm{TG}, \mathrm{mmol} / \mathrm{L}$ & $2.85 \pm 1.08$ & $2.21 \pm 0.96^{\mathrm{b}}$ & $2.83 \pm 1.00$ & $2.68 \pm 0.96^{\mathrm{c}}$ \\
\hline $\mathrm{TC}, \mathrm{mmol} / \mathrm{L}$ & $5.62 \pm 1.34$ & $5.21 \pm 0.99^{d}$ & $5.67 \pm 1.02$ & $5.36 \pm 1.01$ \\
\hline $\mathrm{FPG}, \mathrm{mmol} / \mathrm{L}$ & $5.33 \pm 0.73$ & $5.01 \pm 0.61^{e}$ & $5.27 \pm 0.63$ & $5.17 \pm 0.59$ \\
\hline $\mathrm{HDL}, \mathrm{mmol} / \mathrm{L}$ & $1.37 \pm 0.41$ & $1.34 \pm 0.42$ & $1.43 \pm 0.39$ & $1.41 \pm 0.41$ \\
\hline LDL, mmol/L & $3.43 \pm 0.94$ & $2.96 \pm 0.89^{\mathrm{f}}$ & $3.29 \pm 0.97$ & $3.21 \pm 0.71$ \\
\hline Adiponectin, ug/mL & $13.62 \pm 4.32$ & $16.82 \pm 4.47^{\mathrm{g}}$ & $13.38 \pm 3.21$ & $14.98 \pm 3.92$ \\
\hline CAD-NAFLD & $\mathbf{N}=\mathbf{9 6}$ & $N=151$ & $\mathbf{N}=\mathbf{1 2 0}$ & $\mathbf{N}=\mathbf{1 2 7}$ \\
\hline Age, $y$ & $62.87 \pm 9.65$ & $62.09 \pm 9.87$ & $62.41 \pm 9.51$ & $62.08 \pm 9.61$ \\
\hline Gender, Female/Male & $49 / 47$ & 73/78 & $58 / 62$ & $63 / 64$ \\
\hline Height, m & $1.67 \pm 0.06$ & $1.67 \pm 0.05$ & $1.66 \pm 0.08$ & $1.67 \pm 0.06$ \\
\hline Smoker, No. (\%) & $39(40.6)$ & $65(43.0)$ & $41(34.2)$ & $46(36.2)$ \\
\hline $\mathrm{BMI}, \mathrm{kg} / \mathrm{m}^{2}$ & $24.89 \pm 3.62$ & $25.01 \pm 3.01$ & $24.42 \pm 3.31$ & $24.65 \pm 3.45$ \\
\hline Hypertension, No (\%) & $38(39.6)$ & $60(39.7)$ & $43(35.8)$ & $47(37.0)$ \\
\hline ALT, U/L & $41.02 \pm 21.32$ & $40.61 \pm 20.56$ & $41.45 \pm 20.67$ & $41.21 \pm 20.11$ \\
\hline AST, U/L & $41.34 \pm 22.09$ & $40.21 \pm 21.89$ & $41.01 \pm 21.09$ & $40.56 \pm 21.11$ \\
\hline $\mathrm{TG}, \mathrm{mmol} / \mathrm{L}$ & $2.23 \pm 0.81$ & $2.01 \pm 0.75^{\mathrm{h}}$ & $2.21 \pm 0.76$ & $2.17 \pm 0.69^{\mathrm{i}}$ \\
\hline $\mathrm{TC}, \mathrm{mmol} / \mathrm{L}$ & $5.04 \pm 0.91$ & $5.05 \pm 0.89$ & $5.04 \pm 0.84$ & $5.04 \pm 0.69$ \\
\hline $\mathrm{FPG}, \mathrm{mmol} / \mathrm{L}$ & $5.21 \pm 0.61$ & $4.94 \pm 0.57^{\mathrm{j}}$ & $5.19 \pm 0.21$ & $5.16 \pm 0.22$ \\
\hline $\mathrm{HDL}, \mathrm{mmol} / \mathrm{L}$ & $1.34 \pm 0.32$ & $1.36 \pm 0.41$ & $1.32 \pm 0.25$ & $1.35 \pm 0.32$ \\
\hline $\mathrm{LDL}, \mathrm{mmol} / \mathrm{L}$ & $2.63 \pm 0.67$ & $2.61 \pm 0.68$ & $2.59 \pm 0.65$ & $2.61 \pm 0.67$ \\
\hline Adiponectin, ug/mL & $13.26 \pm 4.21$ & $15.56 \pm 4.31^{\mathrm{k}}$ & $14.26 \pm 3.89$ & $15.63 \pm 4.01$ \\
\hline Controls & $\mathbf{N}=\mathbf{8 5}$ & $N=219$ & $N=119$ & $N=185$ \\
\hline Age, y & $61.09 \pm 9.21$ & $61.23 \pm 9.31$ & $62.21 \pm 9.02$ & $61.59 \pm 9.11$ \\
\hline Gender, Female/Male & $41 / 44$ & $111 / 108$ & $57 / 62$ & $95 / 90$ \\
\hline Height, m & $1.68 \pm 0.07$ & $1.67 \pm 0.09$ & $1.68 \pm 0.07$ & $1.68 \pm 0.08$ \\
\hline Weight, kg & $66.65 \pm 6.32$ & $67.32 \pm 5.94$ & $67.01 \pm 6.01$ & $67.21 \pm 5.45$ \\
\hline Smoker, No. (\%) & $29(34.1)$ & $79(36.1)$ & $45(37.8)$ & $64(34.6)$ \\
\hline
\end{tabular}




\begin{tabular}{|c|c|c|c|c|}
\hline BMI, $\mathrm{kg} / \mathrm{m}^{2}$ & $23.11 \pm 3.21$ & $22.97 \pm 3.01$ & $24.01 \pm 3.41$ & $23.07 \pm 3.01$ \\
\hline Hypertension, No. (\%) & $31(36.5)$ & $80(36.5)$ & $37(31.1)$ & $62(33.5)$ \\
\hline ALT, U/L & $20.31 \pm 7.21$ & $20.56 \pm 6.91$ & $21.21 \pm 7.09$ & $20.56 \pm 6.18$ \\
\hline AST, U/L & $19.71 \pm 7.13$ & $20.81 \pm 8.07$ & $19.76 \pm 7.85$ & $19.81 \pm 8.02$ \\
\hline $\mathrm{TG}, \mathrm{mmol} / \mathrm{L}$ & $1.21 \pm 0.41$ & $1.41 \pm 0.52$ & $1.29 \pm 0.33$ & $1.36 \pm 0.41$ \\
\hline $\mathrm{TC}, \mathrm{mmol} / \mathrm{L}$ & $4.32 \pm 0.81$ & $4.02 \pm 0.71$ & $4.01 \pm 0.36$ & $4.28 \pm 0.52$ \\
\hline $\mathrm{FPG}, \mathrm{mmol} / \mathrm{L}$ & $4.86 \pm 0.42$ & $4.93 \pm 0.31$ & $4.92 \pm 0.41$ & $4.94 \pm 0.44$ \\
\hline $\mathrm{HDL}, \mathrm{mmol} / \mathrm{L}$ & $1.54 \pm 0.46$ & $1.55 \pm 0.41$ & $1.54 \pm 0.42$ & $1.54 \pm 0.42$ \\
\hline $\mathrm{LDL}, \mathrm{mmol} / \mathrm{L}$ & $2.59 \pm 0.76$ & $2.61 \pm 0.71$ & $2.61 \pm 0.76$ & $2.60 \pm 0.68$ \\
\hline Adiponectin, ug/mL & $18.78 \pm 3.21$ & $19.02 \pm 3.11$ & $19.01 \pm 2.97$ & $19.36 \pm 3.02$ \\
\hline
\end{tabular}

${ }^{\mathrm{a}}$ Values are expressed as mean \pm SD unless otherwise indicated.

${ }^{\mathrm{b}} \mathrm{P}=0.031$.

${ }^{\mathrm{c}} \mathrm{P}=0.039$.

${ }^{\mathrm{d}} \mathrm{P}=0.034$

${ }^{\mathrm{e}} \mathrm{P}=0.007$.

${ }^{\mathrm{f}} \mathrm{P}<0.001$.

${ }^{g} \mathrm{P}<0.001$.

${ }^{\mathrm{h}} \mathrm{P}=0.014$.

${ }^{\mathrm{i}} \mathrm{P}=0.042$.

${ }_{\mathrm{j}}^{\mathrm{j}}=0.038$.

${ }^{\mathrm{k}} \mathrm{P}<0.001$. 